\title{
Simulador Virtual de um Sistema de Climatização Baseado na Arquitetura de Redes Neurais Artificiais Cascade-forward
}

\author{
Thamires C. Coutinho*, Orlando D. R. Filho*, \\ Danúbia S. Pires* \\ *Laboratório de Redes de Computadores \\ Departamento de Eletroeletrônica \\ Instituto Federal do Maranhão - IFMA
}

(e-mail: tha.cutrim@gmail.com;orlando.rocha@ifma.edu.br;danubiapires@ifma.edu.br).

\begin{abstract}
The concept of a smart home is being widely disseminated in several areas of society, coupled with the growing use of intelligent systems, it serves as a tool for managing daily tasks, optimizing time and dynamizing the user's relationship with the environment in which he lives, resulting in the rational use of resources and consequently in more comfortable environments. The use of Artificial Neural Networks as a tool to control systems and learning enables data to be processed, thus molding itself to users' habits, learning continuously, and can be implemented in everyday life, from simple systems to the most robust, accelerating validations the same. In this project the simulation was proposed for residential air conditioning, using Artificial Neural Networks with three inputs and three outputs, more specifically the cascade-forward architecture.
\end{abstract}

Resumo: O conceito de casa inteligente está sendo amplamente difundido em diversas faixas da sociedade, isto atrelado com a crescente utilização de sistemas inteligentes, serve como ferramenta de gerenciamento de tarefas cotidianas, otimização do tempo e dinamização da relação do usuário com o meio em que vive, resultando no uso racional de recursos e consequentemente em ambientes mais confortáveis. A utilização de Redes Neurais Artificiais como ferramenta de controle de sistemas e aprendizado possibilita o tratamento de dados, e assim moldar-se aos hábitos dos usuários, aprendendo continuamente, podendo ser implementado no cotidiano, desde sistemas simples até os mais robustos, acelerando as validações das mesmas. Neste projeto foi proposta a simulação para climatização residencial, utilizando Redes Neurais Artificiais com três entradas e três saídas, mais especificamente a arquitetura cascade-forward.

Keywords: Neural networks, Home automation, Control system, Artificial intelligence, Cascade-forward.

Palavras-chaves: Redes neurais artificiais, Automação residencial, Sistemas de controle, Inteligência artificial, Cascade-forward

\section{INTRODUÇÃO}

Domótica é um conceito recente com a proposta de encontrar soluções para tarefas diárias do homem. Os hábitos da população, de um modo geral, tem se modificado como decorrer dos anos, portando a moradia, o abrigo, o lar, deve ser prazeroso, eficiente, dignificante e, por ser um bem de grande vida útil, flexível às transformações sociais e tecnológicas. O uso de novas ferramentas para automação residencial tem sido amplamente difundido, o controle de iluminação, acesso, climatização, comunicação, informática, dentre outros, integrados e comandados por um sistema autônomo, tem demonstrado a possibilidade de tornar o ambiente mais agradável e eficiente. Além disso, há uma redução de tarefas domesticas e o aumento da segurança, pode-se citar também a racionalização do consumo energético (Dias e Pizzolato, 2004). Para Sena (2005), um ambiente inteligente é aquele que aperfeiçoa certas funções inerentes à operações e administração de uma residência ou edifício.
Mediante a isso, o uso de sistemas inteligentes de controle vem com diversas alternativas para automação industrial e residencial. Um sistema de controle consiste em subsistemas e processos (ou plantas) construídos com o objetivo de se obter uma saída desejada com um desempenho desejado, dada uma entrada especificada. Podendo também podem ser utilizados para propiciar conveniência alterando a forma da entrada. Sua vantagem esta, entre outras, a habilidade de compensar perturbações (Nise, 2013). Nesse cenário, o uso de redes neurais artificiais se apresenta como uma alternativa eficaz já que este permite identificar os dados obtidos, separando-os por sua relevância e formando banco de dados para o treinamento e deferimento daquilo que foi proposto, além de possuir a vantagem na sua capacidade de aplicação em sistemas de controle e tomada de decisão para otimização de processos (Pacheco, 1999).

Em (Kochan et al, 2013) é proposto o uso de redes neurais para controle de temperatura do sensor baseado em termopar. Em (Breda, 2016) é apresentada a automação residencial por meio de redes neurais, com enfase na climatização, atraves de 
simulação. Em sua maioria, sistemas de automação residencial comercializados utilizam apenas como parametros: presença ou ausencia do individou e préprogramações já estabelecidas. Baseado em sensores que enviam sinais para a central, tomando assim decisões sobre ligar e desligar o mesmo, deixando de fora informações como dia da semana, incidencia de luz natural no ambiente e temperatura ideal para o individuou.

O crescimento da utilização de redes neurais artificiais como sistema de aprendizado e controle de sistemas pode ser observado em diversas publicações em diversas areas, dentre elas pode-se citar: adaptive PID controller based on Lyapunov Function neural network for time delay temperature control (Aftab, 2015); automação residencial para conservação e eficiência energética por meio de técnicas de inteligência artificial (Goulart, 2017). Portanto, redes neurais artificiais são umas das ferramentas mais importantes para o desenvolvimento de sistemas inteligentes.

\section{PROBLEMATICA}

A ausência do conforto ambiental em residências, de um modo geral, retira a comodidade de permanecer em ambiente residencial. Já que a funcionalidade da casa deixou de ser simplesmente de abrigo. Uma casa hoje não tem mais apenas a função de proteger o homem das intempéries do meio ambiente, ela deve ser capaz de se adaptar às diferentes necessidades que o indivíduo requer em sua contínua evolução (Oliveira, 2016).

Apesar de haver casas com controle artificial, existe a falta de individualidade, já que cada indivíduo possui preferências diferentes, logo desenvolvendo uma inteligência artificial baseada em redes neurais artificiais, tem por finalidade auxiliar no aprendizado e possibilitar ao sistema a capacidade de adaptar-se aos seus usuários de forma individual, ou seja, ele irá padronizar as preferências dos usuários computacionalmente para assim possibilitar distinguir horário de chegada, dias da semana, acarretando na solução do problema da falta de individualismo encontrado em outros sistemas de automação residencial. Isto permite a criação do sistema levando em consideração o padrão não linear de comportamento de seus usuários.

Partindo disto, inserir outros tipos de soluções para esta área em expansão, garante não somente variedade em escolher qual método escolher nesta tecnologia na complexidade do processo, mas também conhecimento em controle onde há muitas entradas e uma única saída.

\section{REFERENCIAL TEORICO}

\subsection{Domotica}

Domotica, também conhecida como automação residencial ou automação doméstica, é uma tecnologia recente responsável pela gestão dos recursos habitacionais e representa o que vem sendo chamado de smart home ou residência inteligente, casa automática, casa inteligente e também retrofitting. Esta tecnologia não tem limites precisos e estáveis, é o resultado da concentração de três dimensões que estão em contínua evolução: tecnológica, social e econômica. Tecnológica por se basear em sistemas eletrônicos. Social por buscar melhor qualidade de vida, comunicação, conforto e segurança para os seus usuários. Econômica porque a inserção nas residências dos equipamentos abre um enorme mercado de consumo.

Devido a esta convergência, a domótica se torna uma tecnologia interdisciplinar, pois ao integrar várias tecnologias à residência, automaticamente são agrupados conhecimentos e competências de diferentes disciplinas e profissionais (Oliveira, 2016).

Segundo Aureside (2005) a automação residencial promove a integração e racionalização dos diversos sistemas existentes em uma residência, relacionados à comunicação, transmissão de dados, iluminação, climatização, segurança, áudio e vídeo, irrigação de jardim, aspiração central, gerando como benefícios: economia, conforto e segurança. Possibilita ainda uma flexibilidade muito grande com relação à múltipla função de uma simples tomada, que pode ser para telefone e num momento seguinte funcionar como ponto de rede, sem a necessidade de passar novos cabos.

Além disso, a domótica proporciona ambientes mais seguros de possíveis acidentes causados por equipamentos, com a desativação remota dos mesmos em casos emergenciais. Para o Instituto Nacional de Meteorologia (INMET), o conforto térmico humano pode ser descrito como:

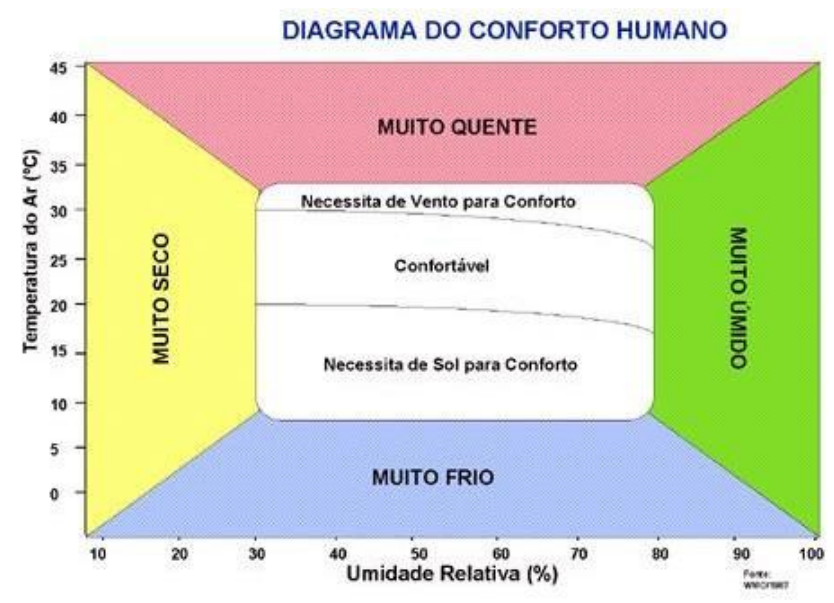

Fig. 1 - Diagrama de conforto térmico humano. Fonte: INMET.

Os atributos de contexto físico são aqueles que garantem o conforto do ponto de vista da integridade física humana. Logo, estariam ligados à ideia de alívio do desconforto consequente das sensações de dor e/ ou insegurança, originados da exposição direta ao ambiente natural e ao perigo. A segurança acaba sendo um atributo de conforto primordial, pois funciona como base para o bem-estar, protegendo o homem contra os efeitos diretos das intempéries (Silva e Santos, 2011).

\subsection{Identificação de Sistemas}


O modelo de um sistema é uma representação mental, física, gráfica ou matemática de observações feitas no mundo real de acordo com certo padrão. A modelagem matemática de sistemas adquire importância especial na solução de problemas de engenharia. Através dos modelos matemáticos pode-se predizer o comportamento dinâmico e estático de um sistema possibilitando simular seu comportamento, sob diversas condições de operação. Com isto podem-se ajustar controladores e/ou estudar formas de melhorar seu desempenho através de simulação dos modelos (Corrêa, 1997).

Segundo Aguirre (2015), o modelo matemático é uma aproximação de apenas algumas características do sistema físico. Em outras palavras, pretender desenvolver um modelo que contenha muitas das características do sistema é um alvo normalmente inatingível. $\mathrm{Na}$ pratica os modelos se aproximam satisfatoriamente do comportamento do sistema para uma determinada aplicação específica e uma faixa de operação limitada. Desta maneira, a automação residencial pode ser implementada de diversas formas, com os mais variados métodos, sem modelo para um determinado sistema, mas diversos modelos para o mesmo.

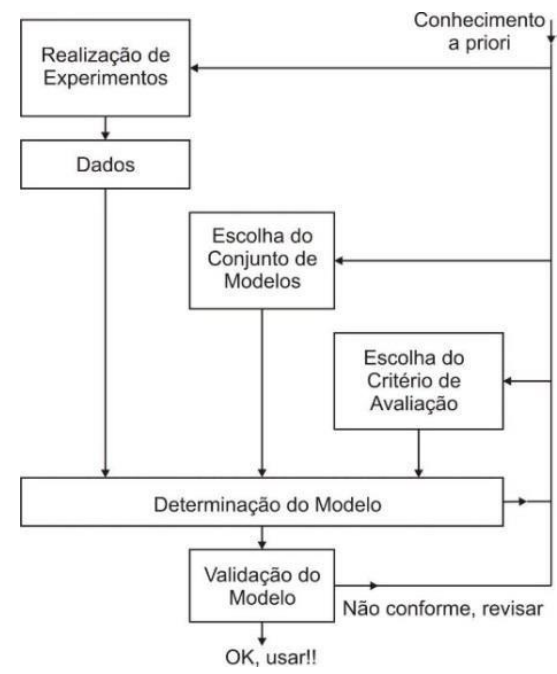

Fig. 2 - Loop de identificação de sistemas. Fonte: Villanueva (2019).

O modelo matemático dinâmico de um sistema é um conjunto de equações que descrevem o seu comportamento dinâmico e estático. A obtenção de um modelo matemático deve estabelecer um compromisso entre a simplicidade do modelo e a precisão dos resultados da análise (Ogata, 1993).

\subsection{Redes Neurais Artificiais}

A habilidade de um ser humano em realizar funções complexas e principalmente a sua capacidade de aprender advêm do processamento paralelo e distribuído da rede de neurônios do cérebro. Os neurônios do córtex, a camada externa do cérebro, são responsáveis pelo processamento cognitivo. Um novo conhecimento ou uma nova experiência pode levar a alterações estruturais no cérebro. Tais alterações são efetivadas por meio de um rearranjo das redes de neurônios, reforçando ou inibindo algumas sinapses (Haykin, 2001).
Portanto, redes neurais artificiais (RNA's) são sistemas que se baseiam no comportamento e a estrutura do cérebro humano, entretanto, possuem um conjunto muito limitado de neurônios. Esses neurônios, por sua vez, processam paralelamente os dados e os propagam através de uma complexa malha de interconexão. Analogamente ao cérebro humano, as RNA's têm a capacidade de interagir com o meio externo e adaptar-se a ele. Essas características conferem as RNA's uma importância multidisciplinar (Finocchio, 2014).

O neurônio artificial possui a funcionalidade de receber uma ou mais entradas, convertendo assim em um sinal de saída. Cada entrada possui um peso e isto determina sua intensidade.

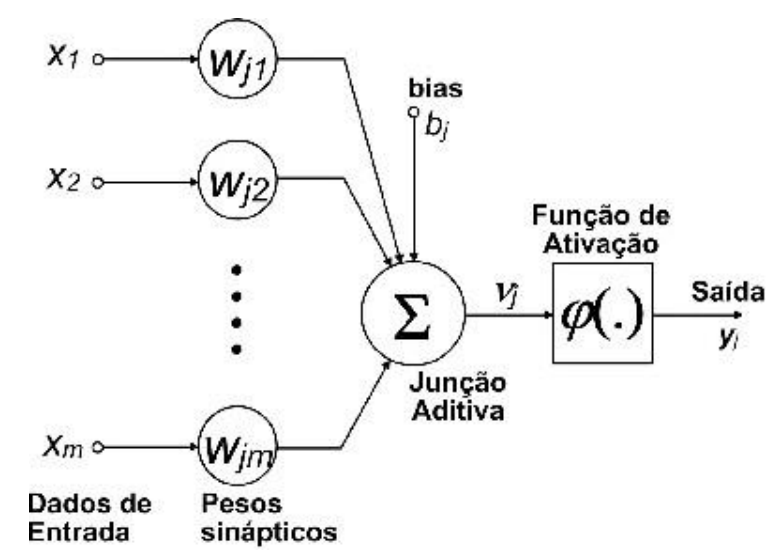

Fig. 3 - Neurônio artificial. Fonte: Haykin (2001).

Os pesquisadores McCulloch e Pitts projetaram a estrutura que é conhecida como a primeira rede neural. Estes propuseram um modelo de neurônio como uma unidade de processamento binária e provaram que esta unidade é capaz de executar muitas operações lógicas. Este modelo, apesar de muito simples, trouxe uma grande contribuição para as discussões sobre a construção dos primeiros computadores digitais, permitindo a criação dos primeiros modelos matemáticos de dispositivos artificiais que buscavam analogias biológicas, ou seja, uma máquina baseada ou inspirada no cérebro humano (Finocchio, 2014). Sua vantagem está na sua capacidade de aplicação em sistemas de controle e tomada de decisão para otimização de processos, garantindo respostas coerentes para dados já então tratados, dependendo apenas de sua competência de aprendizagem e treinamento. Por esses motivos essas técnicas são amplamente empregadas no desenvolvimento de sistemas inteligentes de previsão, suporte à decisão, controle, aperfeiçoamento, modelagem, classificação e reconhecimento de padrões em geral (Pacheco, 1999).

De maneira geral, matematicamente demostra-se um neurônio $\mathrm{k}$ como o seguinte par de equações (1) e (2) (Haykin, 2001):

$$
\mathrm{u}_{\mathrm{k}}=\sum_{\mathrm{j}=1}^{\mathrm{m}} \mathrm{w}_{\mathrm{kj}} \mathrm{x}_{\mathrm{j}}
$$




$$
y_{k}=\varphi\left(u_{k}+b_{k}\right)
$$

Onde $x_{1}, x_{2}, \ldots, x_{m}$ são os sinais de entrada; $\mathrm{w}_{k_{1}}, \mathrm{w}_{k_{2}}, \ldots$, $\mathrm{W}_{k_{m}}$ são os pesos sinápticos do neurônio $k ; u_{k}$ é a saída do combinador linear devido aos sinais de entrada; $b_{k}$ é o bias; $\varphi$ é a função de ativação; $y_{k}$ é o sinal de saída do neurônio.

O conhecimento em redes neurais pode ser descrito genericamente como a informação armazenada ou a modelos utilizados por uma pessoa ou máquina para interpretar, prever e responder apropriadamente ao mundo exterior (Haykin, 2001).

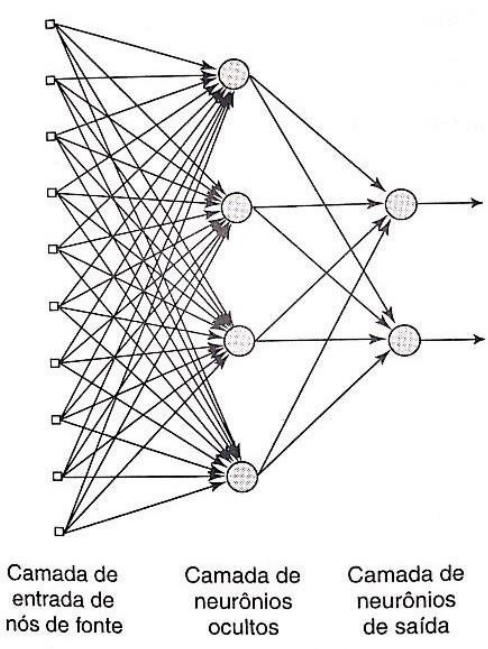

Fig. 4 - Representação de conhecimento em redes neurais. Fonte: Haykin (2001).

Para o mesmo autor a inteligência artificial dentro de redes neurais artificiais tem como objetivo desenvolver paradigmas ou algoritmos que requeiram máquinas para realizar tarefas cognitivas, para as quais os humanos são atualmente melhores. Este sistema deve ser capaz de armazenar conhecimento, aplicar o conhecimento armazenado para resolver problemas e adquirir novo conhecimento através de experiência.

\subsubsection{Perceptron de Múltiplas Camadas}

As redes se múltiplas camadas tem sido aplicados com sucesso para resolução de problemas difíceis, através do seu treinamento de forma supervisionada Haykin (2001). De forma geral, esta configuração pode ser representada como:

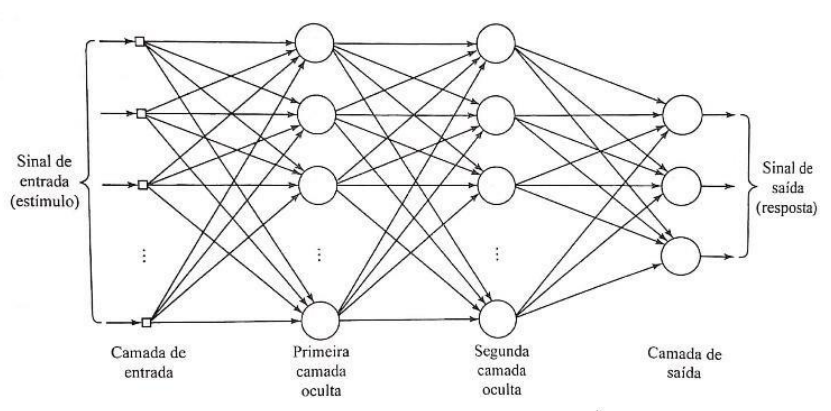

Fig 4 - Representação da arquitetura de um perceptron de múltiplas camadas. Fonte: Haykin (2001).

$\mathrm{O}$ aprendizado supervisionado implica, necessariamente, a existência de um supervisor, ou professor externo, o qual é responsável por estimular as entradas da rede por meio de padrões de entrada e observar a saída desejada. Como a resposta da rede é função dos valores atuais do seu conjunto de pesos, estes são ajustados de ftorma a aproximar a saída da rede da saída desejada (Braga, Carvalo, Ludemir, 2007).

\section{MÉTODOLOGIA}

Em um primeiro momento, foram escolhidas as variáveis de entrada, sendo: temperatura, umidade, luminosidade. Tratando-se de uma simulação, os dados de temperatura e umidade foram obtidos pelo Sistema de Monitoramento Agrometeorológico (Agritempo), por se tratarem de dados reais. Os mesmos se referem ao ano de 2019 dos meses de janeiro à abril. No caso da luminosidade, esta foi definida a partir das NRs para ambientes residenciais e comerciais. A escolhas do referido software se dá por este ser de fácil utilização e possuir uma vasta biblioteca. A arquitetura implementada foi cascade-forward, que se baseia em conexão da entrada e de todas as camadas anteriores para as camadas seguintes. A vantagem deste método é sua capacidade de acomodar a relação não linear entre a entrada e saída, não eliminando a relação linear entre os mesmos (Warsito, 2018). A escolha deste tipo de arquitetura ao invés da feed for-ward, foi a linearidade desta última que não apresenta uma realimentação e em testes realizados, apresentou resultados competentes, mas utilizou uma maior quantidade de vetores e sua regressão linear obteve valores um pouco menores do que a outra arquitetura.

\section{RESULTADOS E DISCUSSÃO}

Antes da implementação da rede propriamente dita, uma primeira simulação foi realizada com cada um dos três parâmetros individualmente, as entradas e targets foram inseridos como vetores para a rede neural. Foram realizados testes para a rede neural, já mostrando resultados individuais satisfatórios. As figuras 6, 7 e 8 demonstram a regressão para os parâmetros escolhidos. Na primeira etapa realizada, são analisadas quão próxima a saída do sistema se aproxima da reta desejada (target). Logo, pode-se afirmar que a precisão é boa para simulação. 

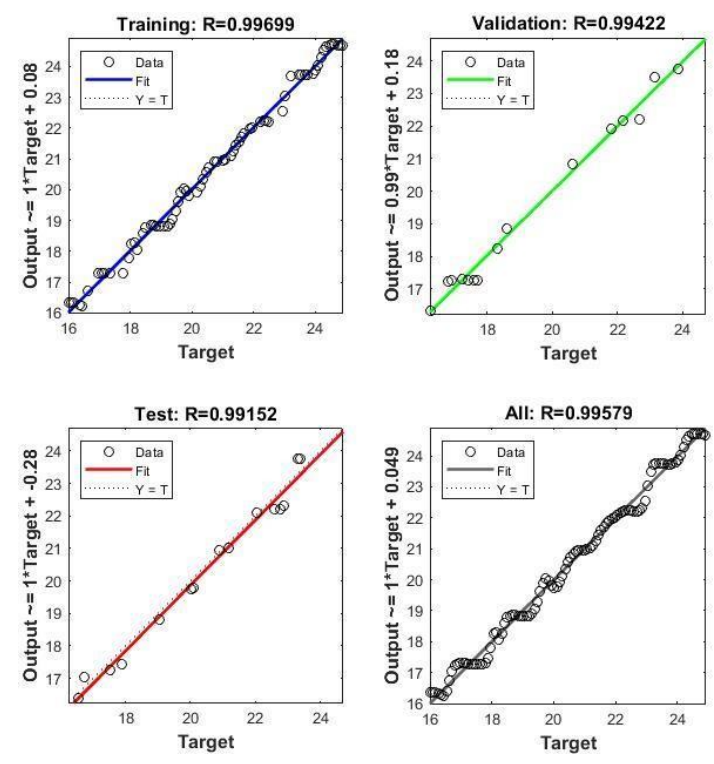

Fig. 5 - Regressão linear para o parâmetro temperatura.
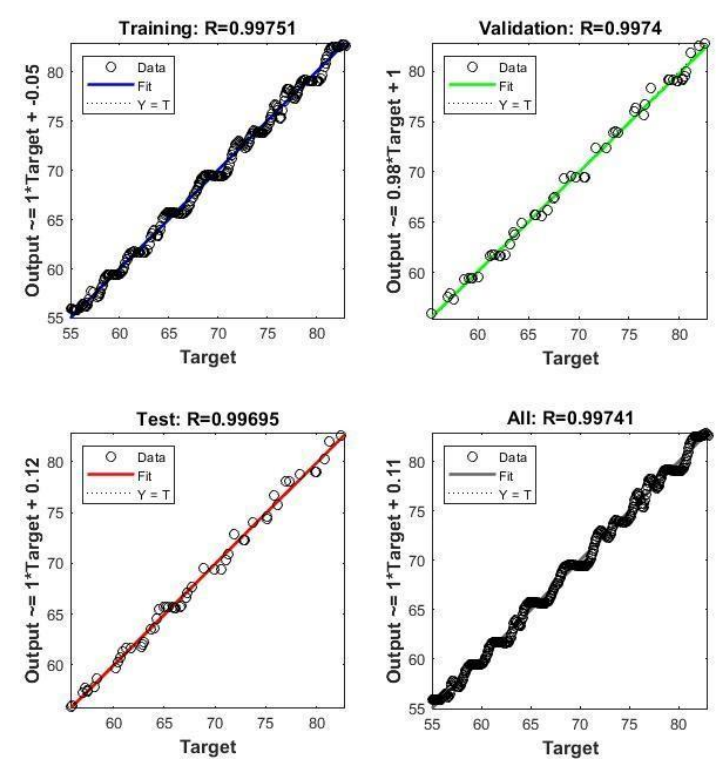

Fig. 6 - Regressão linear para o parâmetro umidade.

Para as redes neurais apresentadas foi usado o algoritmo resilient backpropagation (Rprop), um tipo de aprendizagem supervisionada, mas diferente da back-propagation convencional, esta elimina o problema da derivada próxima de zero. Isto ocorre, pois durante a correção dos pesos é somente utilizado o sinal da derivada. O target foi divido em três conjuntos, usando o dividerand, em: treinamento, validação e teste da rede neural.

As performances das redes foram estimadas com a função mse - função de desempenho de erro normalizado ao quadrado - também conhecido como erro quadrático médio. Para a rede com temperatura o valor de mse é 42, para umidade 73 e para a luminância, 31 .

Observa-se nas regressões mostradas uma aproximação satisfatória dos dados coletados para o target escolhido.
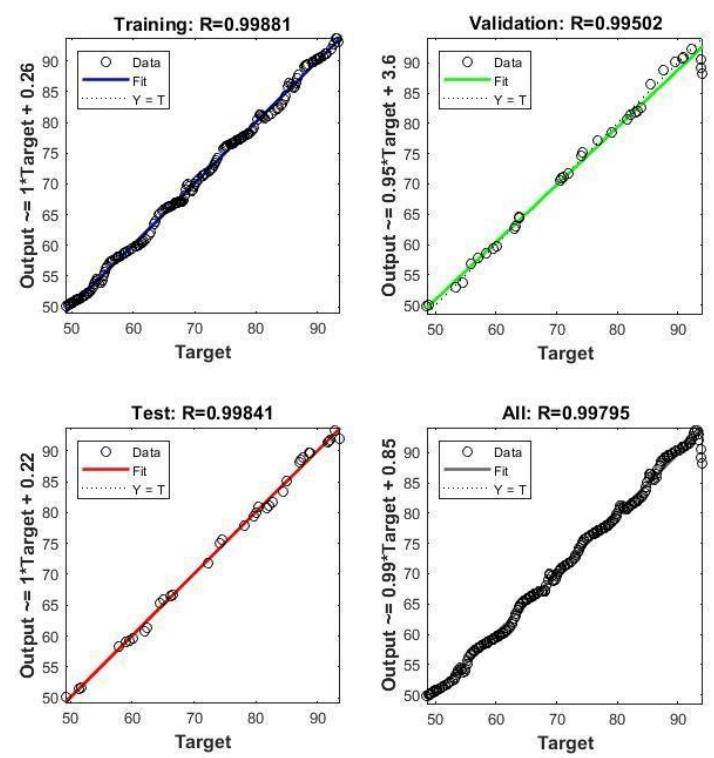

Fig. 7 - Regressão linear para o parâmetro luminosidade.

Em um segundo momento, os inputs e targets resultantes das primeiras redes neurais implementadas foram utilizadas para a criação da rede completa. Esta tornou-se um sistema MIMO - multiple-input and multiple-output - no caso, três entradas e três saídas. Pode-se citar como beneficio deste sistema em detrimento do sistema SISO, single input, single output, a redução de interferência, ganho por diversidade espacial e também multiplexação espacial. O gráfico de regressão linear da figura 9 mostra a eficácia da rede implementada. Assim como nas redes anteriores, o Rprop e dividerand foram utilizadas nesta etapa. A mesma função mse foi aplicada para esta rede, resultando no valor de 46,6001.
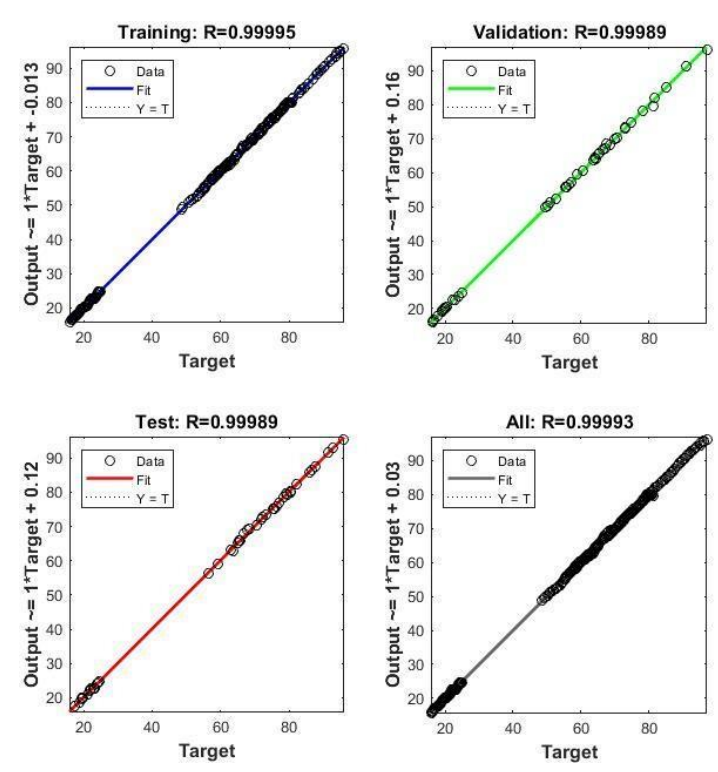

Fig. 9 - Regressão linear da rede neural com os três parâmetros de entrada. 
Em uma etapa posterior, espera-se utilizar sensores para obtenção dos dados e usando um Arduino ou um software simulador de uma planta residencial, testar e implementar a rede simulada, assim como em Breda (2016).

\section{CONCLUSÃO}

Neste trabalho foi proposto a simulação de uma rede neural artificial, visando a automação residencial para o controle de temperatura, umidade e luminosidade. Os testes computacionais realizados comprovam a eficiência da metodologia proposta, ao usar-se modelagem matemática, o operador do sistema tornou-se seguro para proposta, garantindo confiabilidade, robustez e aplicabilidade desta simulação. O estudo contribui para o desenvolvimento de controle de processos e automação, possibilitando outra ferramenta para automação residencial. Além disso, ocorre o enriquecimento da literatura sobre o assunto.

\section{AGRADECIMENTOS}

Os autores agradecem ao Programa Institucional de Bolsa de Iniciação Cientifica do Instituto Federal de Educação, Ciência e Tecnologia do Maranhão - Campus Monte Castelo e a Fundação de Amparo a Pesquisa do Estado do Maranhão pelo apoio financeiro.

\section{REFERÊNCIAS}

Aftab, M. S., and Shafiq, M. Adaptive PID Controller based on Lyapunov Function Neural Network for Time Delay Temperature Control. 8th IEEE GCC Conference and Exhibition, Muscat, Oman, 1-4 February, 2015.

Aguirre, L. A. Introdução à identificação de sistemas: técnicas lineares e não lineares: teoria e aplicação. 5. ed. Belo Horizonte: Editora Ufmg, 2015. 776 p.

Associação Brasileira de Automação Residencial. Tudo sob Controle. Revista Lumière, jun. 2004.

Braga, A. P.; Carvalho; A. P. L. F.; Ludemir, T. B. Redes neurais artificiais: teoria e aplicações. 2.ed. Rio de Janeiro: LTC, 2007. 226p.

Breda, D. C. Automação residencial: aplicação de redes neurais artificiais para controle de climatização. Monografia. Bacharelado em Ciências Computação. UNIVEM, Marília, 2016.

Corrêa, M. V. Identificação de Sistemas Dinâmicos NãoLineares Utilizando Modelos NARMAX Racionais - Aplicação a Sistemas Reais. Dissertação. Mestrado em Engenharia Elétrica. Universidade Federal de Minas Gerais. 1997. Disponível em: https://www.ppgee.ufmg.br/defesas/665M.PDF.

Dias, de A. L. C., Pizzolato, D. N. Domótica:

Aplicabilidade e sistemas de automação residencial. Vértices, v. 6, n. 3, set./dez (2004).

Finocchio, F. A. M. Noções de Redes Neurais Artificiais. Universidade Tecnológica Federal do Paraná. Disponível em: $<$ http://paginapessoal.utfpr.edu.br/mafinocchio/labsi -laboratorio-de-seguranca-e-iluminacao/redesneuraisartificiais/NOCaO\%20DE\%20REDES\%20NEURAI S\%20ARTIFICIAIS.pdf/at_download/file> Acesso em: 08 mar. 2018.

Goulart, T. J. Automação residencial para conservação e eficiência energética por meio de técnicas de inteligência artificial. Trabalho de conclusão de curso. Universidade Federal de Santa Catarina. Florianópolis, 2017.

Haykin, S. Redes Neurais: Princípios e prática. 2. ed. Porto Alegre: Bookman, 2001.

Kochan, O.; Sapojinyk, H.; Kochan, R. Temperature Field Control Method Based on Neural Network. 7th IEEE International Conference on Intelligent Data Acquisition and Advanced Computing Systems: Technology and Applications. Setembro (2013), Berlin, Germany

Nise, N. S . (2013). Engenharia de sistemas de controle. LTC. Rio de Janeiro.

Ogata, K. Engenharia de Controle Moderno. 5. ed.- São Paulo : Pearson Prentice Hall, 2010.

Oliveira, M. U. M. (2016). Domótica: a casa do futuro já presente. Revista Especialize On-line IPOG Goiânia - 12 $2^{\mathrm{a}}$ Edição $\quad \mathrm{n}^{\mathrm{o}} 012$ Vol.01/2016 Dezembro/2016.

Pacheco, M. A. C. Algoritmos genéticos: princípios e aplicações. ICA: Laboratório de Inteligência Computacional Aplicada. Departamento de Engenharia Elétrica. Pontifícia Universidade Católica do Rio de Janeiro. Fonte desconhecida (1999).

Sena, D. C. S. Automação Residencial. 2005.

Projeto de Graduação. 119f. Centro Tecnológico da Universidade Federal do Espírito Santo, Vitória, 2005.

Silva, H. S., and Santos, M. C. O. O significado do conforto no ambiente residencial. Cadernos PROARQ 18.

Warsito, B. et al. Cascade Forward Neural Network for Time Series Prediction. Journal Of Physics: Conference Series, [s.1.], v. 1025, p.012097-012097, maio 2018. IOP Publishing.http://dx.doi.org/10.1088/17426596/1025/1/012097. 